Our sponsor, NatWest, provided three mentors for each school, to support their business ideas, how to maximise income from their fundraising and events, and covered the cost.

In January, a launch evening gave all schools the opportunity to meet each other and their mentors, and start discussing their ideas. We held two progress meetings to offer encouragement and support to the students. The schools visited the hospice to understand our work and how they were making a difference.

At the awards evening, schools presented their experiences over the 11 weeks to a panel of judges, including what they had learnt about the hospice and new skills they had developed. We were overwhelmed with the positive feedback from students, schools and parents. The Project raised over $£ 17,000$ and two schools did not reach their $£ 1,500$ target. The Five 0 Project will now become an annual fundraising initiative for secondary schools for our hospice.

\section{P-30 LOVE YOUR LOCAL HOSPICE - A COLLABORATION FOR THE FUTURE}

${ }^{1}$ Elizabeth Clarke, ${ }^{2}$ Laura Smith, ${ }^{3}$ Diane Parkes. ${ }^{1}$ Douglas Macmillan Hospice; ${ }^{2}$ Birmingham St Mary's Hospice, Birmingham, UK; ${ }^{3}$ John Taylor Hospice

\subsection{6/bmjspcare-2016-001245.54}

In February 2016, 16 West Midlands adult and children's hospices joined forces to launch an advertising campaign to raise awareness, dispel myths and encourage our communities to Love Your Local Hospice.

Community engagement was the key focus, and based on learning from the North West Hospice TV campaign we decided to focus on general awareness-raising rather than fundraising. Individual goals were put aside to achieve the joint ambition of reaching a wider audience. The agreed common themes were care, family, love, life, friendship, and being there for the whole community whenever they need us. The overarching objective was that all hospices were buying into a longer-term sustainable collaboration.

The TV advert aired for 10 days on ITV and reached almost 1.5 million people across the region. It also ran for one month via ITV on Demand with a click through rate of $1.66 \%$ (double the normal rate) reaching over 90,000 people.

To support the advert a website was created with links to all individual hospices. A social media campaign also ran alongside utilising bespoke films for each hospice. This joint activity had an additional reach of over 300,000 people. Hospices also ran their own events and activities to align with the campaign. The campaign achieved over 35 pieces of media coverage and was featured on Midlands Today and local radio.

The success of the campaign has meant the cohesive effort continues with plans underway for a second awareness campaign in October followed by a joint income generation campaign scheduled for 2017.

The Love Your Local Hospice model has been developed so that other hospices can benefit by investing into the campaign content at a reduced cost rather than setting such a campaign up from scratch.

In conclusion the campaign demonstrated that a collective voice is stronger than one. A FOUNDATION FOR ACHIEVING OUR VISION

Rebecca Speight. St Wilfrid's Hospice, Eastbourne, UK

\subsection{6/bmjspcare-2016-001245.55}

Introduction Our vision is to empower people to be able to talk about death and dying which will result in people making choices about how and where they die and to empower communities to take control of their deaths. There is a similarity between community engagement programmes, and how our retail company can help the hospice reach that vision. We cannot assume that all communities are confident, and have the skills or language, to talk about death and dying. We have an opportunity to support this. Our shops are our beacons in the community. They allow us to interact with the community that is not immediately outside, or inside, our hospice door. If we are able to harness our presence on the high street, inform, educate and empower it will benefit us twofold; increased support and increased individual choice about death.

Aim

- Embed ourselves within the communities that we work in

- Empower communities and build resilience through our retail company

- Encourage communities to harness this to talk openly about death and dying

- Build social capital, which supports the community and helps reach our organisational goal

Approach

- Use our shop windows to promote hospice work

- Engage with local communities - building skill and confidence through volunteering programmes, expand the volunteer demographic to encourage intergenerational conversations.

- Gather 'real' stories from people in our communities, who are dealing with death/dying, who have been impacted by our shops e.g., conversations with retail teams

- Align our work with that of the hospice; philanthropic shopping that directly benefits members of their community

Measuring success

- Apply concepts of asset based community development when reviewing our impact on resilience

- Use principles of social capital to guide/measure the activities of the retail company

- Develop retail company 'outcomes' in addition to monetary targets

- Gather community case studies to understand impact.

\section{P-32 BUILDING A COMPASSIONATE COMMUNITY - NEW WAYS OF PARTNERING FOR COMMUNITY EMPOWERMENT}

${ }^{1}$ Sarah Riches, ${ }^{2}$ Jacqueline Kelly. ${ }^{1}$ St Giles Hospice, Lichfield, UK; ${ }^{2}$ Katharine House Hospice, Stafford, UK

\subsection{6/bmjspcare-2016-001245.56}

'A population health approach to palliative care is the most under developed at this stage of palliative care service development. Yet it is the approach that has the most potential to enhance the quality of life and wellbeing to the widest number of people in sickness and in health, in dying and in loss, and in all caring experiences toward one another' (PHPCI, 2014). 